\title{
The role of a virtual avatar in attention and memory tasks in Rett syndrome
}

\author{
Rosa Angela Fabio ${ }^{1 *} \mathbb{D}$, Giorgia Pergolizzi ${ }^{1}$, Andrea Nucita², Giancarlo lannizzotto ${ }^{2}$ and Tindara Caprì
}

\begin{abstract}
Background: Since subjects with Rett syndrome (RTT) focus their attention mainly on the faces of people with whom they interact, in this study the role of a human-like smart interactive agent (an avatar) in enhancing cognitive processes is examined. More in depth, this study aimed to understand if, and to what extent, the use of an avatar can improve attention and memory abilities in subjects with RTT.

Method: Thirty-six subjects with RTT participated in the study. All participants performed over-selectivity and memory tasks, for a total of six trials. These trials were randomly presented in two different conditions: with and without virtual avatar.

Results: The results indicated that the participants improved their attention and memory abilities when they performed the tasks with the avatar. There were no improvements when they performed the tasks without the avatar.

Discussion: The results were discussed considering the relationship between motivation, attention and memory in RTT.
\end{abstract}

Keywords: Rett syndrome, Avatar, Attention, Memory, Over-selectivity

\section{Background}

Rett syndrome (RTT) is a complex genetic neurological disorder, caused by mutations in the X-linked gene encoding for a regulator of epigenetic gene expression, methyl CpG binding protein (MeCP2). The clinical picture of RTT is defined by loss of hand use and language, with the development of gait abnormalities and hand stereotypies [1-4]. Thus, subjects with RTT often use their eyes to communicate [5-7]. Neurological abnormalities in RTT are reflected in several behavioral and cognitive impairments such as stereotypies, loss of speech and hand skills, gait apraxia, irregular breathing with hyperventilation while awake, and frequent seizures [1-4]. Clinical features of RTT suggest that this disorder is the result of a primary disturbance of neuronal development,

\footnotetext{
* Correspondence: rafabio@unime.it

${ }^{1}$ Department of Experimental and Clinical Medicine, University of Messina, Via Bivona, 98122 Messina, Italy

Full list of author information is available at the end of the article
}

resulting in maturation arrest in selected brain regions [8]. For example, this maturation arrest could be caused by defective neurotransmitter systems that fail to provide normal trophic factors [8].

New promising approaches have recently shown that technology-aided programs for subjects with severe/profound and multiple disabilities are useful in enabling performance of daily tasks and improving cognitive abilities [9]. Technology-aided programs together with cognitive rehabilitation can enhance neuroplasticity both with neuropsychological and neurophysiological parameters. Fabio et al. (2016) [10] investigated modifications in behavior and brain activity of patients with RTT by using eye-tracking technology during a discrimination task, while neurophysiological parameters were measured using quantitative EEG (QEEG) analysis. This study showed that patients with RTT become attentive and vigilant to the task and look at the target more quickly and for a longer time. This result was supported 
by QEEG analysis, that revealed a decrease of beta activity and an increase of right asymmetry. Hence, the study evidenced a positive effect of the application of eyetracking technology to cognitive rehabilitation on behavioral and neurophysiological parameters in RTT.

Spaghero [9], in a study exploring virtual reality, demonstrated that subjects with intellectual disabilities can present a marked improvement in attention when interacting with virtual objects and events. Therefore, this new approach has been recognized, as it provides a safe environment in which any individual can enjoy pleasurable activities, music [9] and communicating with the family [11]. Another major advantage in using technology-aided interventions is the possibility to acquire huge amounts of data, essential for advanced data analysis such as predictive analysis [12].

A new trend in current technologies is the presentation of a sequence of tasks within a environment, with an avatar giving positive feedback to the subjects on the correct completion of a task, thereby improving motivation [1316]. Avatars, in the form of graphical characters, able to show human-like facial expressions and gestures, to speak and even react to users' interaction by interpreting gestures, emotional states and speech, have been exploited for several applications in the past [17]. Furthermore, virtual environments have often been combined with advanced human-computer interaction $(\mathrm{HCI})$ technologies to facilitate user interaction in complex tasks [18].

The use of avatars has been shown to be effective in increasing attention in various disabilities [19-21], however, it has not yet been explored for people with RTT. For example, a study [22] investigated the emotion recognition ability in subjects with autism using an avatar able to recreate emotional facial expressions. Further evidence was provided by experimenting with an avatar in Attention Deficit/Hyperactivity Disorder (ADHD) [23-28]. These studies suggest that an avatar can be used as a computerized pedagogical agent with realistic characteristics; for example, it can appear on a computer screen and guide users through multimedia learning environments, designed to support learning and direct attention to relevant topics. In the study [23], a virtual avatar similar to a young male nerd was created for teaching ADHD subjects, providing options for solving mathematic and logic problems. Results of this study suggested that it could be possible to elicit greater attention in subjects with ADHD and highlight how the presence of a pedagogical agent may improve the performance of subjects.

The role of a computerized pedagogical agent is also supported by other theories. According to Computers Are Social Actors (CASA), for example, people respond to the media in the same way they would respond to humans, so the avatar would become a real social model $[29,30]$. Wang, Wenjing and Heping [31] also states that people learn better from multimedia presentations in the presence of a pedagogical agent, recognizing social presence. For these reasons, the use of the avatar becomes effective for students to structure the appropriate processes and improve attention and learning [32] by strengthening their interests [33].

Other evidence on the role of the virtual avatar were provided in a study [21] in which subjects with ADHD underwent three experimental conditions. In the first condition, the avatar simply provided instructions; in the second condition the avatar presented the instructions and also provided feedback on the student's attention; in the third condition the avatar was not presented. Results showed that the presence of the virtual avatar increased the problem-solving ability of the subjects. These benefits were also confirmed in the work of Shema-Shiratzky, Brozgol CornejoThumm [34]. Summarizing, avatars showing behaviours that the users feel as familiar [35] can become real tutors, coaches, motivators, mentors, models to emulate [36].

This study aims to examine whether the use of an avatar can improve attention and memory abilities in subjects with RTT. The underlying logic is that the motivation process significantly affects some cognitive functions, such as attention and memory. Since subjects with RTT are very motivated to look at the face of therapists and parents, an avatar acting human-like gestures, speech, gaze and behaviors may be very motivating to join in the learning process.

Attention and memory tasks were presented with two conditions through eye tracking technology. In the first condition, the avatar gave the instructions and asked the patient to give the answer. In the second condition there was no avatar. A voice gave the instruction and solicited the replies. The hypothesis was open: on one hand it may be that the avatar, acting as a social motivational model [30] can induce subjects with RTT to focus and memorize more efficiently; on the other hand, based on the redundancy theory of Mayer [29], since the avatar is a third element it may be that it acts like a distractor and, not necessarily improve attention and memory.

Furthermore, since the eye tracking methodology helps to distinguish the encoding phase (with the registration of the length of fixations) and the retrieval phases (with the number of items recalled), in this study we want to understand if the avatar is effective in the encoding phase or in the retrieval phase or both. As shown in previous studies with ADHD children[21, 23] we expect that, if the subjects with RTT show a high level of length of fixation in the condition with the avatar, such a condition will produce benefits also in the retrieval phase.

\section{Method}

\section{Participants}

Forty-one subjects with a diagnosis of RTT took part in the experiment. Forty were female and one was male. 
Their families had been contacted by the Italian association for Rett syndrome (AIRETT) that asked them to participate in the study. The families come from all over Italy. Five subjects were excluded from the study since they were not able to focus on the stimuli of the monitor. For this reason, finally, 36 subjects participated in the study. They ranged in age between 4 and 36 years. A general assessment was carried out by a psychologist through the Vineland Adaptive Behaviour Scale (VABS)[37] and the Rett Syndrome Rating Scale (RARS) [38]. Thirty-one subjects and one male attended schools or socio-educational centres; four subjects were assisted by an educator at home. All showed little or no purposeful hand use and pervasive hand stereotypies were striking. Ambulation was preserved in 19 subjects. Table 1 shows the chronological age of the participants, the RARS scores as well as the VABS Scores.

\section{Material}

A Tobii Series-I eye-tracker was used to record the participants' visual scanning. This tool records the following ocular movements: the location and duration of ocular fixations (pause of eye movement on an object of interest) and saccadic movements (rapid movements between fixations). Passive gaze tracing (LC Technologies, Sao Paulo, Brazil) software was used to generate gaze data during visuals scanning. It was possible to choice the areas of interest (AOI) within the images chosen for the statistical analysis of eye tracking. An AOI cluster can be defined as selected specific areas that are used for both attention and recalling details of the images.

The eye-tracker was used for both the overselectivity paradigm and the memory paradigm. The avatar was created using an educational platform "Voki for Education" (https://www.voki.com/). Voki is a free collection of customizable speaking avatars for teachers and educators that allows users to create a precise profile of a talking character. Voki is created by Oddcast and can be customized to look like humans, cartoons, and/or animals.

The characteristics selected for the creation of the avatar were chosen through a pre-calibration, carried out during the 2018 Airett Campus in which several subjects with RTT spent their holidays with family and educators. The pre-calibration was fundamental as it allowed to include the avatar that the RTT subjects prefer. Following, the materials of both paradigms will be presented.

\section{Memory paradigm}

The memory test was implemented. The story-cartoon presented with Tobii eye-tracker was easy to understand and remember, and the descriptions of facts were presented in a logical order. Four cartoon sequences were extracted, two from the "ant Bibi" and two from the
"Pimpa on the beach" animation movies, respectively. They were chosen out of seven cartoon sequences presented to 31 3-year-old children and calibrated based on their comprehension of the story $(>90 \%)$ and on their recalling indices $(>90 \%)$. The questions have various levels of difficulty, from simple recognition of the main character of the story, to recognition of the emotional states of the characters, to identification of the actions within the story.

Each cartoon sequence contained 8 significant memory indices (Table 2). Both cartoon sequences "Ant Bibi" and "Pimpa on the Beach" lasted 2:30 min.

The test was carried out for each patient. After each cartoon was presented through the eye-tracker, the participants were asked to perform immediate recall of the cartoon with a recognition test with 8 questions regarding the story (Table 3 ).

For each of the relevant indexes two cards were presented on the screen, the correct response (CR) and the distractor answer. The scores were 1 or 0 : if the response was corrected, 1 score, if the response was the distractor stimulus, 0 score.

\section{Overselectivity paradigm}

In this paradigm, 2 cards of $10 \mathrm{~cm} \times 30 \mathrm{~cm}$, each one reporting a different complex stimulus composed of three familiar objects shown in black and white, were presented on the screen of the Tobii eye-tracker. In the second phase, individual stimuli, consisting of cards of about $10 \mathrm{~cm} \times 10 \mathrm{~cm}$, were presented on the screen. Each card represented a single familiar object previously included in the target complex stimulus (Fig. 1). The cards were calibrated in a previous study [39]. In the condition with virtual avatar, the avatar presented both the complex stimuli and the individual stimuli between which the participant had to choose (Fig. 2, phase 1 and 2). In the condition without virtual avatar, no avatar was presented to participants.

\section{Vineland adaptive behavior scales-interview second edition (VABS)}

The VABS is subdivided into four domains: communication, daily living, socialization and motor skills. The interviewer asks general questions pertaining to the patient's functioning in each domain and uses the responses to rate the examinee on each critical behaviour item (2: always present, 1: sometimes present, 0 : seldom or never present). Typical interviews require approximately $1 \mathrm{~h}$. A total score is computed by summing the individual ratings for each scale. The reliability of VABS was established as follows: split-half, $0.73-0.93$ for the communication domain, $0.83-0.92$ for daily living skills, 0.78-0.94 for socialization, 0.70-0.95 for motor skills, 0.84-0.98 for adaptive behaviour composite, 0.77-0.88 
Table 1 Descriptive characteristics of the patients with Rett Syndrome

\begin{tabular}{|c|c|c|c|c|c|}
\hline Clinical stage & Age & MeCP2 Mutation & RARS $^{1}$ scores & Level of ${ }^{2}$ severity & VABS $^{3}$ scores \\
\hline$\|$ & 4 & R306C & 66.5 & Moderate & 83 \\
\hline$\|$ & 4 & R255X & 80.5 & severe & 40 \\
\hline$\|$ & 4 & PT158M & 52.5 & Moderate & 60 \\
\hline$\|$ & 4 & R306C & 74 & Moderate & 50 \\
\hline$\|$ & 4 & / & 71.5 & Moderate & 56 \\
\hline III & 5 & R294X & 66.5 & Moderate & 80 \\
\hline III & 5 & P322A & 58.5 & Moderate & 75 \\
\hline III & 7 & / & 47.5 & Moderate & 60 \\
\hline III & 7 & R168X & 51.5 & Moderate & 82 \\
\hline III & 8 & / & 48.5 & Mild & 121 \\
\hline III & 8 & R133C & 35 & Mild & 140 \\
\hline III & 10 & FOXG1 & 86.5 & severe & 35 \\
\hline III & 10 & T158M & 81 & Severe & 33 \\
\hline III & 11 & R255X & 66 & Moderate & 83 \\
\hline III & 12 & R306C & 69 & Moderate & 88 \\
\hline III & 12 & R306C & 59 & Moderate & 84 \\
\hline III & 13 & S355fsX37 & 63.50 & Moderate & 110 \\
\hline III & 14 & / & 56 & Moderate & 58 \\
\hline III & 14 & R270X & 61.5 & Moderate & 76 \\
\hline III & 14 & P322A & 52.5 & Moderate & 86 \\
\hline III & 16 & T158M & 71 & Moderate & 92 \\
\hline III & 16 & $168 \mathrm{RX}$ & 62 & Moderate & 131 \\
\hline III & 16 & $\mathrm{R} 133 \mathrm{C}$ & 64.5 & Moderate & 110 \\
\hline III & 17 & arg168stop & 37 & Mild & 121 \\
\hline III & 18 & / & 67.5 & Moderate & 107 \\
\hline III & 19 & R255C & 74.5 & Moderate & 84 \\
\hline III & 20 & CDLK5 & 61 & Moderate & 56 \\
\hline III & 20 & P322L & 58.7 & Moderate & 105 \\
\hline III & 22 & P389X & 66.5 & Moderate & 84 \\
\hline III & 26 & R270X & 56.5 & Moderate & 65 \\
\hline IV & 29 & R255C & 72 & Moderate & 86 \\
\hline IV & 29 & R135C & 39 & Mild & 168 \\
\hline IV & 31 & R255C & 59.5 & Moderate & 165 \\
\hline IV & 35 & / & 47 & Mild & 118 \\
\hline IV & 36 & T158M & 59 & Moderate & 63 \\
\hline
\end{tabular}

${ }^{1}$ Rett Assessment Rating Scales (RARS)

${ }^{2}$ Levels of severity according to the total scores of RARS (Mild $=0-55$; Moderate $=56-81$; Severe $=>81$ )

${ }^{3}$ Vineland Adaptive Behaviour Scales-Interview second edition (VABS)

for maladaptive behaviour. The interrupter reliability coefficients for the survey and expanded forms ranged from 0.62 to 0.75 . Standard error of measurement ranged from 3.4 to 8.2 over the four domains, and from 2.2 to 4.9 for the Adaptive Behaviour Composite, on the survey form. The VABS was obtained for use in this study because it was bought by the University of Messina.
Rett assessment rating scales (RARS)

The RARS is a standardized scale used to evaluate patients with RTT. It is organized into seven domains: cognitive, sensorial, motor, emotional, autonomy, typical characteristics of the disease and of behaviour. Typical characteristics of the disease and behaviour domains measure the following characteristics: mood swings, convulsions, dyspnoea, hyperactivity, anxiety, aggressivity, 
Table 2 Significant indexes of cartoon sequence

\begin{tabular}{ll}
\hline Ant Bibi & Pimpa on the Beach \\
\hline Main character & Main character \\
Secondary character & Action of Pimpa \\
Colour of main character & Secondary character \\
Ant character & Action on the beach \\
Action of Pimpa & Emotions of Pimpa \\
Underground & Crayfish character \\
Emotions of Pimpa & Underground \\
Final action & Final action \\
\hline
\end{tabular}

bruxism, oculogyric crises, epilepsy, aerophagia, muscle tension and food preferences. A total of 31 items was generated as representative of the profile of RTT. Each item is provided with a brief glossary explaining its meaning in a few words. Each item is rated on a 4-point scale, where 1 = within normal limits, 2 = infrequent or low abnormality, 3 = frequent or medium-high abnormality, and $4=$ strong abnormality. Intermediate ratings are possible, for example, an answer between 2 and 3 points is rated as 2.5. For each item, the evaluator circles the number corresponding to the best description of the patient. After a patient has been rated on all 31 items, a total score is computed by summing the individual ratings. This total score allows the evaluator to identify the level of severity of RTT, conceptualized as a continuum ranging from mild symptoms to severe deficits (Mild $=0-55$; Moderate $=56$ 81; Severe $=>81$ ). The RARS was established by a standardization procedure, involving a sample of 220 patients with RTT, proving that the instrument is statistically valid and reliable. Skewness and kurtosis values, calculated for the distribution of the total score, are 0.110 and 0.352 , respectively. Distribution is found to be normal. Cronbach's alpha is used to determine the internal consistency for the whole scale and sub-scales. Total alpha is 0.912 , and the internal consistency of the sub-scales is high (from 0.811 to 0.934 ).

\section{Procedure}

The experiment was carried out in a quiet room during the 2019 Rett summer campus of the AIRETT. The examiner administered the VABS and the RARS through an interview with the parents of the subjects with RTT and the educators. Participants sat in a dimly lit room of the association in front of the eye-tracker screen at $30 \mathrm{~cm}$ and the direction of the gaze was determined according to the Pupil Centre/Corneal Reflection Method in low-intensity infrared light.

The eye tracker was positioned in such a way that ambient lighting did not affect the recordings. The eye tracking equipment was calibrated for each participant at the beginning of the experiment. Gaze fixations of at least $1000 \mathrm{~ms}$ within a region of $2^{\circ}-3^{\circ}$ around each calibration point were considered accurate.

The two tasks of this experiment were presented randomly in two conditions with and without avatar, as given in Tables 4 and 5. All participants performed overselectivity and memory tasks. There were six trials: four different stories-cartoon of "Pimpa" in the memory task, and two over-selectivity trials with different familiar stimuli. These trials were randomly presented in two

Table 3 Questions related to the significant indexes of the cartoon sequence

\begin{tabular}{|c|c|}
\hline Ant Bibi-1 & Pimpa on the Beach-1 \\
\hline 1. Who was the main character of the story? & 1. Who was the main character from the story? \\
\hline 2. Who met Pimpa at the beginning of the story? & 2. What was Pimpa doing? \\
\hline 3. What colour was Pimpa? & 3. Did Armando want to play with Pimpa? \\
\hline 4. Who met Pimpa? & 4. Who did Pimpa play with on the beach? \\
\hline 5. What was Pimpa taking the sack or the bucket? & 5. Was Pimpa sad or happy? \\
\hline 6. Were there clouds or stars? & 6. Who did you meet after the Pimpa? \\
\hline 7. How happy or sad was Pimpa? & 7. Were there sun or stars? \\
\hline 8. What did Pimpa do at the end of the story? & 8. What did Pimpa do in the end? \\
\hline Ant Bibi-2 & Pimpa on the Beach-2 \\
\hline 1. Who was the main character of the story? & 1. Who was the main character of the story? \\
\hline 2. What the colour was the sky? & 2. What the colour was the Pimpa's ball? \\
\hline 3. Who met Pimpa? & 3. Was there a boat or a car? \\
\hline 4. What Ant Bibi give her? & 4. What the colour was the boat? \\
\hline 5. Shoes were clear or unclear? & 5. What did the boat do? \\
\hline 6. What ate Pimpa and Ant Bibi? & 6. How happy or sad was Pimpa? \\
\hline 7. How happi or sad was Pimpa? & 7. Were there sun or stars? \\
\hline 8. What did Pimpa do at the end of the story? & 8. What did Pimpa do at the end of the story? \\
\hline
\end{tabular}




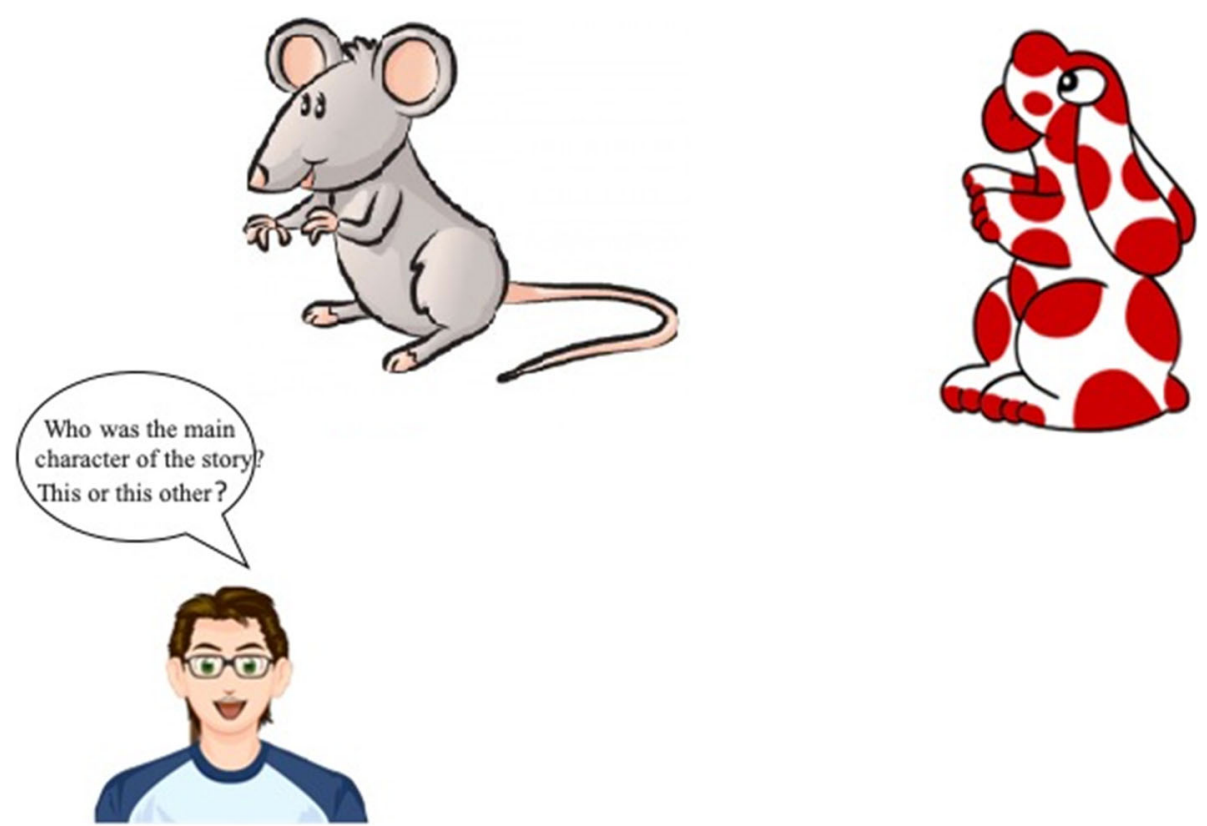

Fig. 1 Recognition test: target and distractor. The images in Figs. 1,2 and 3 were created by two co-authors using Nero PhotoSnap for Windows 10 (https://it.all10soft.com/nero-photosnap-windows-10/). The images are freely available

conditions (with and without virtual avatar). The experiment lasted $30 \mathrm{~min}$ in total.

\section{Measures}

Memory task: fixation length (FL) of the correct stimuli related to the significant memory indices during the vision of the cartoon and the number of the recalled correct indexes. FL refers to the amount of time (seconds) spent by the subject when looking at the correct stimulus. Total fixation length refers to the sum of the time spent in looking at each significant index during the vision of the cartoon. Fixations were extracted using a threshold of $100 \mathrm{~ms}$.

Overselectivity task: FL of the complex correct stimulus and the number of the individual correct recalled images.

\section{Statistical analyses}

The data were analysed using SPSS version 22.0 for Mac. The descriptive statistics of the dependent

\section{First phase}

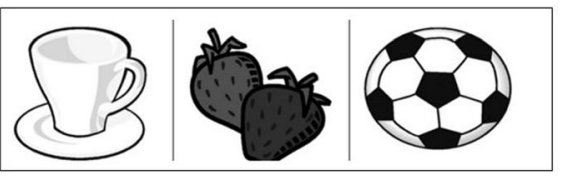

Complex stimulus target

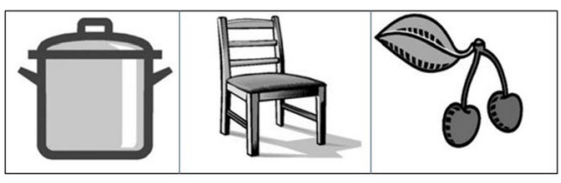

Complex stimulus distactors

Second phase

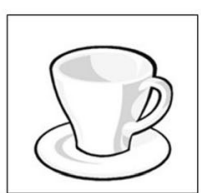

Individual stimulus target

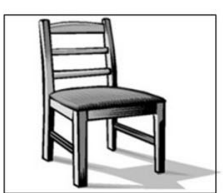

Individual stimulus distractor

Fig. 2 Overselectivity stimuli. The images in Figs. 1, 2 and 3 were created by two co-authors using Nero PhotoSnap for Windows 10 (https://it.all1 0soft.com/nero-photosnap-windows-10/). The images are freely available 


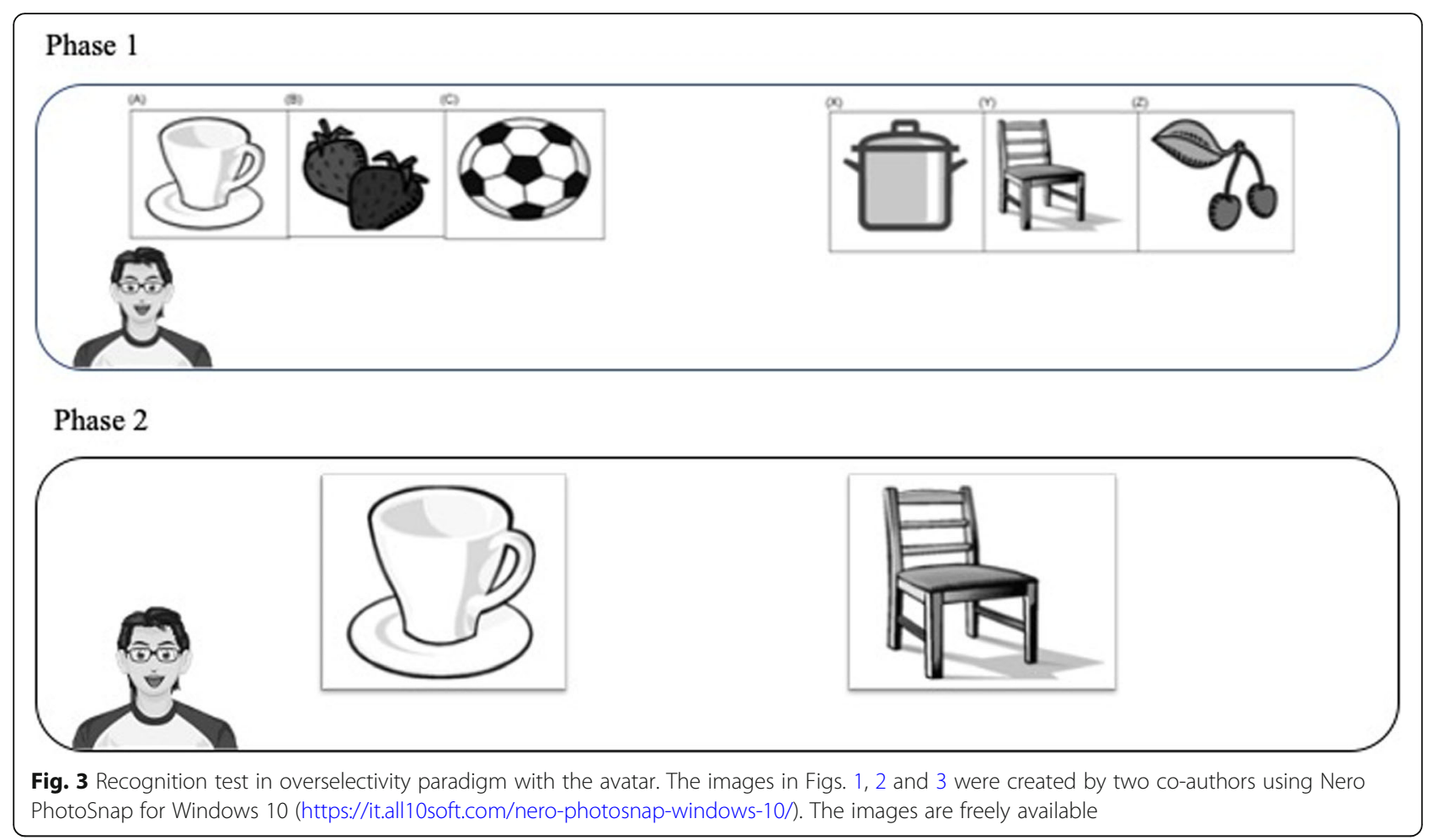

variables were tabulated and examined. Alpha level was set to 0.05 for all statistical tests. In the case of significant effects, the effect size of the test was reported. The relationship between continuous variables was evaluated by determining Pearson's r; group comparisons were conducted using t-test for paired samples.

\section{Results}

With reference to the memory paradigm, a preliminary analysis showed that the two cartoons "Ant Bibi" and "Pimpa on the Beach" showed no statistical differences either with reference to fixation length of the total correct stimuli, $\mathrm{t}(35)=1.1, p=.43$, or the number of the correct recalled indexes, $\mathrm{t}(35)=0.76, p=.67$; for this reason in the following statistical analysis the mean of indexes of both cartoons is used. Table 6 shows means and standard deviations of the two conditions.
With reference to the length of the total correct stimuli results show significant differences, $\mathrm{t}(35)=4.55$, $p<.0001$. This means that the time spent in looking at each significant index during the vision of the cartoon was higher when the avatar helped the subjects than when the avatar was not present. With reference to the number of the recalled correct indexes, results show significant differences, $\mathrm{t}(35)=6.02, p<.0001$. Subjects with RTT recall more significant indexes when the avatar is present than when it is absent.

With reference to the overselectivity paradigm, FL of the complex correct stimulus show significant differences, $\mathrm{t}(35)=6.61, p<.001$. This means that the time spent in looking at the correct complex stimulus was higher when the avatar was present than when the avatar was not present. With reference to the number of the individual correct recalled images, results show significant

Table 4 Memory task procedure

\begin{tabular}{ll}
$\begin{array}{l}\text { Experimental } \\
\text { condition }\end{array}$ & Procedure \\
\hline With avatar & The avatar appeared initially on the whole screen of the Tobii l-15 and said "Hi, my name is Giorgio. Watch this cartoon with \\
& me!" \\
& Then the avatar became smaller and moved to the lower left part of the screen. During the cartoon, it only moves its eyes \\
& and head in a stereotyped way to make the avatar seem alive. \\
& After watching the first cartoon, the avatar appeared again and says "Hello, we will play together now!" \\
& Then the avatar started by asking the participant the 8 questions. Participants had to choose the correct answer with their \\
& eyes and avoid focusing on the distractor. \\
& Then the avatar appeared again and repeated the process with a second video. \\
& No avatar was presented to participants. The story-cartoon was presented with Tobii eye-tracker. \\
Without avatar &
\end{tabular}


Table 5 Overselectivity paradigm procedure

$\begin{array}{ll}\begin{array}{l}\text { Experimental } \\ \text { condition }\end{array} & \begin{array}{l}\text { In the first phase, two images placed } 40 \mathrm{~cm} \text { from each other, reporting complex stimuli (ABC, correct stimulus; XYZ, incorrect } \\ \text { stimulus (Fig. 2) were presented. } \\ \text { The examiner presented each subject with the correct complex stimulus described as the "correct one"; both the correct and } \\ \text { incorrect cards were then presented on the screen in front of each subject who was subsequently asked: "Which is the } \\ \text { correct one?" } \\ \text { Forty-five seconds were allowed to answer the question. The subjects could answer by grasping an image or by looking at it. } \\ \text { If the subject chose the correct card (ABC) during the } 45 \mathrm{~s} \text {, the examiner gave them a verbal reinforcement (e.g. "Great!" "Very } \\ \text { good!"). If the subject chose the incorrect image (XYZ) or did not choose any image during } 45 \text { s, both were removed, and the } \\ \text { 'no' answer was coded. A new possibility of choice started after } 10 \text { s. } \\ \text { In the second phase, the examiner used the cards reporting individual objects extracted both by correct and incorrect } \\ \text { complex stimuli by devising } 9 \text { different pairs of individual stimuli from the combination of A with Y, B with X etc. The } \\ \text { examiner asked every participant to choose the correct stimulus. } \\ \text { The avatar presented both the complex stimuli and the individual stimuli between which the participant had to choose } \\ \text { (phase } 1 \text { and 2). }\end{array} \\ \text { With avatar }\end{array}$

differences, $\mathrm{t}(35)=7.01, p<.0001$. Subjects with RTT recall more significant indexes when the avatar is present than when it is absent. Table 7 shows means and standard deviations of the parameters of the overselectivity task in the two conditions.

With reference to the second question here addressed, the avatar helps both encoding and retrieval phases. Pearson's coefficient $r$ was chosen as the measure of the strength of correlation. With reference to the memory task, the relationship between FL of the correct stimuli and the number of correctly recalled indexes is high, $\mathrm{r}(35)=.678, p<.001$. By comparing the level of severity (RARS) with FL and the number of corrected response in the condition with avatar, they showed statistically significant differences correlations, $\mathrm{r}$ $(35)=-.446, p<.001 ; \mathrm{r}(35)=-.548, p<.001$. No statistically significant correlations between memory parameters, age and VABS were found.

With reference to the overselectivity task, the relationship between FL of the complex correct stimulus and the number of the individual correct recalled images is high, $\mathrm{r}$ $(35)=.52, p<.001$. Compared with RARS, FL and CR showed statistically significant correlations in the condition with avatar, $\mathrm{r}(35)=-.404, p<.05 ; \mathrm{r}(35)=-.478$, $p<.001$. No statistically significant correlations between overselectivity parameters, age and VABS were found.

In the condition without avatar, no significant correlations between the two tasks, age, RARS and VABS were found.

Table 6 Means (M) and Standard deviations (SD) of the parameters of the memory task

\begin{tabular}{lll}
\hline Conditions & Parameters & M (SD) \\
\hline With Avatar & fixation length of the total correct stimuli & $26.37(12.95)$ \\
& number of the recalled correct indexes & $5.23(1.10)$ \\
Without Avatar & fixation length of the total correct stimuli & $15.95(11.82)$ \\
& number of the recalled correct indexes & $3.23(1.99)$ \\
\hline
\end{tabular}

\section{Discussion}

This study addressed two questions: whether the avatar can act as a social motivational model and improve attention and memory and whether it is redundant acting like a distractor and disrupting attention and memory. Both results, related to the two paradigms here analysed, showed that subjects with RTT had a high level of length of fixation in the condition with the avatar and this produced benefits also in the retrieval phase. In addition, the results of the present study indicated that patients with RTT, when performing the two tasks in the condition with avatar, presented a statistically significant improvement in attention and memory abilities. Moreover, correlational analysis between the level of severity of RTT and the two tasks (memory and overselectivity paradigms) showed significant negative relationships. This indicates that at higher levels of severity, the performance of patients with RTT decrease. Thus, there is a relationship between the clinical status of the patients who participated in the study and the test results.

Taken together, these findings indicate that the avatar acts as a cognitive strengthener. Our results support the role of the avatar in learning environments and in the attention process, as social model. These results are in line with the CASA theory. This theory assumes that people respond to the media in the same way they would respond to humans [29]. Wang's theory also states that learning can be optimized by the presence of a pedagogical agent on the screen [31]. For these reasons, the use of the avatar becomes effective for subjects with RTT to structure the appropriate processes and improve their attention and their learning [40-46].

In line with this [47-49], our avatar not only gives instructions on the relevant aspects of the coding phase but also helps the subjects to better recall the contents. Hence, our results indicate that an interactive avatar that helps subjects with RTT to better direct their attention can concretely improve cognitive performance.

The limitations of the present study are related to the graphical, behavioural, and technological characteristics 
Table 7 Means (M) and Standard deviations (SD) of the parameters of the overselectivity task

\begin{tabular}{lll}
\hline Conditions & Parameters & M (SD) \\
\hline With Avatar & fixation of the complex correct stimuli & 28.51 (9.22) \\
Without Avatar & number of correct individual stimuli recalled & $6.19(2.33)$ \\
& fixation of the complex correct stimuli & $18.32(11.01)$ \\
\hline
\end{tabular}

of the avatar and the sample size. With reference to the characteristics of the avatar, they can affect the performance of subjects with RTT, so it is important to understand what technological, graphical and behavioural conditions are necessary to improve the performance. With reference to the size of the sample, there may be constraints to the generalizability of the results because the sample size is small. However, given that the effect size is adequate, the results can be considered reliable.

The present work can be considered a preliminary experiment. Future studies are needed to understand the conditions under which an avatar can improve the learning process of subjects with RTT. In addition, future research could consider the correlation found in this study, between the severity level of RTT and the cognitive performance of the subjects, as confounding factors. Furthermore, it could be interesting to replicate this study with neurological measurements, such as brain activity, in order to verify whether the avatar can also act as a social motivational model and improve attention and memory at neurological level.

\section{Conclusion}

We consider the findings reported in this article a relevant contribution to the introduction of a new generation of embodied interactive avatars aimed at supporting subjects with RTT in their everyday activities [50, 51]. These findings can help families and educators to identify what software can be effectively used to help children and girls with RTT, and also software designers to make good evidencebased choices to offer more focused software, capable of giving significant performance improvements [52-60].

\section{Abbreviations}

AOI: Areas of interest; ADHD: Attention Deficit/Hyperactivity Disorder; CASA: Computers Are Social Actors; FL: Fixation length; HCl: Humancomputer interaction; AIRETT: Italian association for Rett syndrome; RTT: Rett syndrome; RARS: Rett Syndrome Rating Scale; VABS: Vineland Adaptive Behaviour Scale

\section{Supplementary Information}

The online version contains supplementary material available at https://doi. org/10.1186/s12883-021-02212-w.

\section{Additional file 1:.}

\section{Acknowledgements}

The authors thank the AIRETT and the CARI (Airett Center for innovation and Research) of Verona for the help in recruiting patients.

\section{Authors' contributions}

RAF and GP designed the study. RAF and GP recruited the participants. TC diagnosed the participants. TC and GP assessed the participant with the experimental tasks. RAF, AN and $\mathrm{Gl}$ analysed the data, RAF, GP, AN, GI and TC wrote the manuscript. All authors read and approved the final manuscript.

\section{Funding}

The authors received no funding for this work.

\section{Availability of data and materials}

We enclosed the full data set as additional supporting file. We had the permission to use the VABS because it was bought by the University of Messina.

\section{Declarations}

\section{Ethics approval and consent to participate}

All procedures performed in studies involving human participants were in accordance with the ethical standards of the institutional and/or national research committee and with the 1964 Helsinki declaration and its later amendments or comparable ethical standards. The study design was approved by the Human Ethics Committee of Cognitive Science,

Psychological, Educational and Cultural Studies of the University of Messina (Protocol n. 20015_36). All the parents of the children who took part in the study signed a written consent form.

\section{Consent for publication}

Not applicable.

\section{Competing interests}

On behalf of all authors, the corresponding author states that there is no conflict of interest.

\section{Author details}

'Department of Experimental and Clinical Medicine, University of Messina, Via Bivona, 98122 Messina, Italy. ${ }^{2}$ Department of Cognitive Sciences, Psychological, Educational and Cultural Studies, University of Messina, Via Concezione, 6, 98122 Messina, Italy.

Received: 30 November 2020 Accepted: 26 April 2021

Published online: 14 June 2021

\section{References}

1. Djukic A, Rose SA, Jankowski JJ, Feldman JF. Rett syndrome: recognition of facial expression and its relation to scanning patterns. Pediatr Neurol. 2014; 51(5):650-6. https://doi.org/10.1016/j.pediatrneurol.2014.07.022.

2. Fabio RA, Giannatiempo S, Caprì T. Attention and identification of the same and the similar visual stimuli in Rett Syndrome. Life Span Disabil. 2019; XXII(1):113-27.

3. Fabio RA, Giannatiempo S, Oliva P, Murdaca AM. The increase of attention in Rett syndrome. A pretest-post test research design. J Dev Phys Disabil. 2011;23(2):99-111. https://doi.org/10.1007/s10882-010-9207-z.

4. Romano A, Caprì T, Semino M, Bizzego I, Di Rosa G, Fabio RA. Gross motor, physical activity and musculoskeletal disorder evaluation tools for Rett syndrome: a systematic review. Dev Neurorehab. 2019;23(8):485-501. https://doi.org/10.1080/17518423.2019.1680761.

5. Fabio RA, Caprì T, Nucita A, lannizzotto G, Mohammadhasani N. Eye gaze digital games to improve motivational and attentional ability in Rett Syndrome. J Spec Educ Rehab. 2018, 2019;9(3-4):105-26. https://doi.org/1 0.19057/jser.2019.43 
6. Fabio RA, Caprì T, Buzzai C, Pittalà V, Gangemi A. Auditory and Visual Oddball Paradigm Evaluated Through P300 in Five Subjects with Rett Syndrome. Neuroquant. 2019;17:40-9. https://doi.org/10.14704/nq.2019.17. 07.2591.

7. Zhang B, Zhou Z, Zhou Y, Zhang T, Ma Y, Niu Y, et al. Social-valence-related increased attention in rett syndrome cynomolgus monkeys: an eye-tracking study. Autism Res. 2019;12(11):1585-97. https://doi.org/10.1002/aur.2189.

8. Armstrong D, Dunn JK, Antalffy B, Trivedi R. Selective dendritic alterations in the cortex of Rett syndrome. J Neuropath Exp Neur. 1995;54(2):195-201. https://doi.org/10.1097/00005072-199503000-00006.

9. Spanghero F, Ferrari V, Pozzobon V, Rebellato F. Tecnologie per l'inclusione robotica. Tecnologie per l'inclusione. 2016;17:37-9.

10. Fabio RA, Billeci L, Crifaci G, Troise E, Tortorella G, Pioggia G. Cognitive training modifies frequency EEG bands and neuropsychological measures in Rett syndrome. Res Dev Disabil. 2016;53-54:73-85. https://doi.org/10.1016/j. ridd.2016.01.009.

11. Fabio RA, lannizzotto G, Nucita A, Caprì T. Adult listening behaviour, music preferences and emotions in the mobile context. Does mobile context affect elicited emotions? Cogent Eng. 2019;6(1):1-17. https://doi.org/10.1 080/23311916.2019.1597666.

12. Caprì T, Gugliandolo MC, lannizzotto G, Nucita A, Fabio RA. The influence of media usage on family functioning. Curr Psychol. 2019;(23):1-10. https://doi. org/10.1007/s12144-019-00204-1.

13. Nucita A, Bernava GM, Giglio P, Peroni M, Bartolo M, Orlando S, et al. Lecture notes in computer science. Int Conf Model Data Eng. 2013;8216: 225-2363. https://doi.org/10.1007/978-3-642-41366-7_19.

14. Annaz D, Campbell R, Coleman M, Milne E, Swettenham J. Young children with autism spectrum disorder do not preferentially attend to biological motion. J Aut Dev Disord. 2011;42(3):401-8. https://doi.org/10.1007/s10803011-1256-3.

15. Diehl JJ, Schmitt LM, Villano M, Crowell CR. The clinical use of robots for individuals with autism spectrum disorders: a critical review. Res Aut Spect Disord. 2012;6(1):249-62. https://doi.org/10.1016/j.rasd.2011.05.006.

16. Kumazaki H, Warren Z, Swanson A, Yoshikawa Y, Matsumoto Y, Yoshimura Y, et al. Brief report: evaluating the utility of varied technological agents to elicit social attention from children with autism Spectrum disorders. J Autism Dev Disord. 2019;49(4):1700-8. https://doi.org/10.1007/s10803-018-3 841-1.

17. Pierno AC, Mari M, Lusher D, Castiello U. Robotic movement elicits visuomotor priming in children with autism. Neuropsychologia. 2008;46(2): 448-54. https://doi.org/10.1016/j.neuropsychologia.2007.08.020.

18. lannizzotto G, Lo Bello L, Nucita A, Grasso GM. A vision and speech enabled, customizable, virtual assistant for smart environments. Proceedings 11th. Int Conf Hum Syst Interact. 2018:50-6.

19. Iannizzotto G, La Rosa F, Costanzo C, Lanzafame P. A multimodal perceptual user interface for collaborative environments. Lecture Notes Comput Sci. 2005;3617:115-22. https://doi.org/10.1007/11553595_14.

20. Dautenhahn K. Socially intelligent robots: dimensions of human-robot interaction. Philos Trans R Soc Lond Ser B Biol Sci. 2007;362(1480):679-704. https://doi.org/10.1098/rstb.2006.2004.

21. Fabio RA, Caprì T, lannizzotto G, Nucita A, Mohammadhasani N. Interactive avatar boosts the performances of children with attention deficit hyperactivity disorder in dynamic measures of intelligence. Cyberpsychol Behav Soc. 2019;22(9):588-96 https://doi.org/10.1089/cyber.2018.0711.

22. Mantziou O, Vrellis I, Mikropoulos TA. Do children in the spectrum of autism interact with real-time emotionally expressive human controlled avatars? Proced Comput Sci. 2015;67:241-51. https://doi.org/10.1016/j.procs.2015.09.268.

23. Mohammadhasani N, Fardanesh H, Hatami J, Mozayani N, Fabio RA. The pedagogical agent enhances mathematics learning in ADHD students. Educ Info Tech. 2018:23:1-11.

24. Mohammadhasani N, Fabio RA, Fardanesh $\mathrm{H}$, Hatami J. The link between visual attention and memory in ADHD and normally developing students: seeing is remembering? Reti. Saperi e Linguaggi Ita J Cogn Scie. 2015;1(2): 89-102.

25. Fabio RA. The study of automatic and controlled processes in ADHD: a reread and a new proposal. Med J Clin Psy. 2017;5:1-8.

26. Martino G, Caprì T, Castriciano C, Fabio RA. Automatic deficits can lead executive deficits in ADHD. Med J Clin Psychol. 2017;5(3):1-32. https://doi. org/10.6092/2282-1619/2017.5.1669.

27. Fabio RA, Caprì T, Mohammadhasani N, Gangemi A, Gagliano A, Martino G. Frequency bands in seeing and remembering: comparing $\mathrm{ADHD}$ and typically developing children. Neuropsychol Trends. 2018;24(24):97-116. https://doi.org/10.7358/neur-2018-024-fabi.

28. Fabio RA, Caprì T. Automatic and controlled attentional capture by threatening stimuli. Heliyon. 2019;5(5):17-52. https://doi.org/10.1016/j. heliyon.2019.e01752.

29. Mayer RE. Cognitive theory of multimedia learning. In: Mayer R, editor. The Cambridge handbook of multimedia learning. New York: Cambridge University Press; 2014. p. 34-71.

30. Kim Y, Baylor. A social-cognitive framework for pedagogical agents as learning companions. Educ Tec Res Dev. 2007;54:569-96.

31. Wang F, Wenjing LI, Heping XIE, et al. Is pedagogical agent in multimedia learning good for learning? A meta analysis. Adv Psyc Scie. 2017;25(1):12. https://doi.org/10.3724/SP.J.1042.2017.00012.

32. Kinnebrew J, Biswas $G$, Sulcer B, et al. Investigating self-regulated learning in teachable agent environments. In: Azevedo R, Aleven V, editors. International handbook of metacognition and learning technologies. Amsterdam: Springer; 2013. p. 451-70. https://doi.org/10.1007/978-1-44195546-3_29.

33. Lusk MM, Atkinson R. Animated pedagogical agents: does their degree of embodiment impact learning from static or animated worked examples? Appl Cogn Psychol. 2007;21(6):747-64. https://doi.org/10.1002/acp.1347.

34. Shema-Shiratzky S, Brozgol M, Cornejo-Thumm P, Geva-Dayan K, Rotstein M, Leitner $Y$, et al. Virtual reality training to enhance behavior and cognitive function among children with attention-deficit/hyperactivity disorder: brief report. Dev Neuroreha habil. 2019;22(6):431-6. https://doi.org/10.1080/1751 8423.2018 .1476602 .

35. Schroeder $\mathrm{N}$, Adesope OO. A case for the use of pedagogical agents in online learning environments. J Teac Lea Tech. 2012;1:43-7.

36. Veletsianos G, Russell GS. Pedagogical agents. In: Spector JM, editor. Handbook of research on educational communications and technology. New York: Springer Science + Business Media; 2013. p. 759-69.

37. Sparrow SS, Cicchetti DV, Balla DA. Vineland adaptive behavior scales: second edition (Vineland II), the expanded interview form. Pearson Assessments: Livonia; 2008.

38. Fabio RA, Martinazzoli C, Antonietti A. Costruzione e standardizzazione dello strumento "R.A.R.S." (Rett Assessment Rating Scale). Ciclo Evol Disabil. 2005;8: 257-381.

39. Fabio RA, Giannatiempo S, Antonietti A, Budden S. The role of stereotypies in overselectivity process in Rett syndrome. Res Dev Disabil. 2008;30(1):13645. https://doi.org/10.1016/j.ridd.2008.01.003.

40. Antonietti A, Fabio RA, Boari G, Bonanomi A. The"style of learning and thinking" (SOLAT) questionnaire: psychometric data for reliability and validity of Italian version. Test Psy Method. 2005:4:299-316.

41. Castelli I, Antonietti A, Fabio RA, Lucchini B, Marchetti A. Do Rett syndrome persons possess theory of mind? Some evidence from non-treated subjects. Life Span Disab. 2013;2:157-68.

42. Fabio RA. Attention measures of patients with rett syndrome need to overcome the challenges in evaluating the oculomotor function using electronystagmography. Eur J Paediatr Neurol. 2019;23(2):232. https://doi. org/10.1016/j.ejpn.2019.02.008.

43. Fabio RA, Caprì $T$. The executive functions in a sample of Italian adults with ADHD: attention, response inhibition and planning/organization. Med J Clin Psyc. 2017;5(3):1-17. https://doi.org/10.6092/2282-1619/2017.5.1636.

44. Fabio RA, Gangemi A, Caprì T, Budden S, Falzone A. Neurophysiological and cognitive effects of Transcranial direct current stimulation in three subjects with Rett syndrome with chronic language impairments. Res Dev Disabil. 2018;76:76-87. https://doi.org/10.1016/j.ridd.2018.03.008.

45. Fabio RA, Magaudda C, Caprì T, Towey G, Martino G. Choice Behavior in Rett Syndrome, the consistency parameter. Life Span Disabil 2018;XXXI (1): 47-62.

46. Fabio RA, Martino G, Caprì T, et al. Long chain poly-unsaturated fatty acid supplementation in Rett syndrome: a randomized placebo-controlled trial. Asian Clin Nutr. 2018;10(1):37-46. https://doi.org/10.3923/ajcn.2018.37.46.

47. Heidig S, Clarebout G. Do pedagogical agents make a difference to student motivation and learning? Educ Res Rev. 2011;6(1):27-54. https://doi.org/10.1 016/j.edurev.2010.07.004

48. Kim Y, Baylor A. Simulating instructional roles through pedagogical agents. I J Arti Intell Educa. 2005;15:95-115.

49. Payr S. The virtual university's faculty: an overview of educational agents Appl Arti Intell An. 2003;17(1):1-19. https://doi.org/10.1080/713827053.

50. Gangemi A, Caprì T, Fabio RA, Puggioni P, Falzone AM, Martino G. Transcranial Direct Current Stimulation (tDCS) and Cognitive Empowerment 
for the functional recovery of diseases with chronic impairment and genetic etiopathogenesis. In Kevin V. Urbano editors. Advances in Research. New York: Nova Science Publisher; 2018. ISBN: 978-153613265-6;978-1536132649.

51. Fabio RA, Caprì T, Lotan M, Towey GE, Martino G. Motor abilities are related to the specific genotype in Rett Syndrome. In Kevin V. Urbano Editors. Advances in Genetics Research. New York: Nova Science Publisher; 2018 ISBN: 978-153613265-6;978-153613264-9.

52. Prosperi M, Min JS, Bian J, Modave F. Big data hurdles in precision medicine and precision public health. BMC Med Inform Decis Mak. 2018;18(1):139. https://doi.org/10.1186/s12911-018-0719-2

53. Parker J, Mawson S, Mountain G, Nasr N, Zheng H. Stroke patients' utilisation of extrinsic feedback from computer-based technology in the home: a multiple case study realistic evaluation. BMC Med Inform Decis Mak. 2014:46. https://doi.org/10.1186/1472-6947-14-46(1).

54. Iannizzotto G, Bello L, Nucita A, Grasso GM. A Vision and Speech Enabled, Customizable, Virtual Assistant for Smart Environments 11 th International Conference on Human System Interaction (HSI) Gdansk 2018; 50-56. doi: https://doi.org/10.1109/HSI.2018.8431232.

55. Caprì T, Fabio RA, lannizzotto G, Nucita A. The TCTRS project: A holistic approach for telerehabilitation in rett syndrome. Electronics (Switzerland). 2020;9:3.

56. Mohammadhasani N, Caprì T, Nucita A, lannizzotto G, Fabio RA. Atypical visual scan path affects remembering in ADHD. J Int Neuropsychol Soc 2020;26(6):557-66. https://doi.org/10.1017/S135561771900136X.

57. Iannizzotto G, La Rosa F, Costanzo C, Lanzafame P. A multimodal perceptual user interface for video-surveillance environments. Proceedings of the Seventh International Conference on Multimodal Interfaces, ICMI'05 2005; $45-52$.

58. Iannizzotto G, Nucita A, Fabio RA, Capri T, Lo BL. Remote eye-tracking for cognitive telerehabilitation and interactive school tasks in times of COVID19. Information. 2020;11(6):296-304. https://doi.org/10.3390/info 11060296.

59. Capri T, Nucita A, lannizzotto G, Stasolla F, Romano A, Semino M, et al. Telerehabilitation for improving adaptive skills of children and young adults with multiple disabilities: a systematic review. Rev J Autism Dev Disord. 2020:1-11. https://doi.org/10.1007/s40489-020-00214-x.

60. Lancioni G, Singh N, O'Reilly M, Sigafoos J, Boccasini A, La Martire ML, et al. People with multiple disabilities use assistive technology to perform complex activities at the appropriate time. Int J Disabi Hum Dev. 2016;15(3): 261-6. https://doi.org/10.1515/ijdhd-2015-0012.

\section{Publisher's Note}

Springer Nature remains neutral with regard to jurisdictional claims in published maps and institutional affiliations.

Ready to submit your research? Choose BMC and benefit from:

- fast, convenient online submission

- thorough peer review by experienced researchers in your field

- rapid publication on acceptance

- support for research data, including large and complex data types

- gold Open Access which fosters wider collaboration and increased citations

- maximum visibility for your research: over $100 \mathrm{M}$ website views per year

At $\mathrm{BMC}$, research is always in progress.

Learn more biomedcentral.com/submissions 